\title{
A "TEXTURA ABERTA DO DIREITO" DE HART ENQUANTO INDETERMINAÇÃO DADA POR UM DUPLO ASPECTO DA LINGUAGEM E PELA DERROTABILIDADE
}

\section{Catharine Black Lipp João*}

Resumo: O presente artigo pretende apresentar algumas hipóteses sobre o que seria a "textura aberta do Direito" proposta por H.L.A Hart e quais seriam as suas implicações no âmbito da decisão judicial. Nesse contexto, serão apurados aspectos que dizem respeito à textura aberta da própria linguagem (tanto em um viés semântico ou técnico, quanto em um contextualizado) e à derrotabilidade jurídica, para fins de verificar se estariam relacionadas àquilo que Hart entendeu ao se utilizar da expressão. O método de abordagem é o indutivo e a técnica de pesquisa é a bibliográfica.

Palavras-Chave: Textura Aberta. Derrotabilidade. Discricionariedade Judicial. Indeterminação Jurídica. Linguagem.

\section{THE HARTIAN "OPEN TEXTURE OF LAW" AS INDETERMINACY GIVEN BY A DOUBLE ASPECT OF LANGUAGE AND BY DEFEASIBILITY}

\begin{abstract}
The present article intends to present some hypotheses about what could be the "open texture of Law" proposed by H .L. Hart and what would be its implications in the scope of judicial decision. In this context, will still be determined aspects that relate to the open texture of the language itself (both in a semantic or technical view, and in a contextualized one) and to the legal defeasibility, in order to verify if they are related to what Hart understood by open texture of Law. The method of approach is inductive and the research technique is bibliographical.
\end{abstract}

Keywords: Open Texture. Defeasibility. Judicial Discretion. Legal Indeterminacy. Language.

\section{Introdução}

The law is a sort of hocus-pocus science, that smiles in yer face while it picks yer pocket; and the glorious uncertainty of it is of mair use to the professor than the justice of it.

(Charles Macklin, Love à la mode, act ii. sc. 1, 1759)

Não obstante decorridos mais de 50 anos desde a primeira edição publicada da obra que objetiva clarificar o quadro geral do pensamento jurídico, O Conceito de Direito (1961), e dos

* Advogada. Mestranda em Direitos Indisponíveis na Fundação Escola Superior do Ministério Público, sob orientação do Professor Doutor Anízio Pires Gavião Filho. Endereço eletrônico: catharinejoao@ gmail.com

Revista de Teorias do Direito e Realismo Jurídico | e-ISSN: 2525-9601 | Porto Alegre | v. 4 | n. 2 | p. 21 - 37 | Jul/Dez. 2018 
artigos The Ascription of Responsibility and Rights (1948) e Positivism and the Separation of Law and Morals (1958), todos escritos de H.L.A Hart, observa-se que as teorias neles apresentadas ainda são atuais e relevantes enquanto objetos de estudo de diversos aspectos do Direito por um incontável número de juristas, seja para o fim de adoção de suas ideias, seja para o fim de, a partir delas, elaboração de hipóteses outras que as refutem.

Um dos pontos considerados por Hart diz respeito àquilo que o autor chama de "textura aberta" do Direito, cuja compreensão sobre os seus contornos e a concordância com a sua existência até hoje não são aspectos alcançados sem controvérsias, sendo alvos de profunda discussão na doutrina. A expressão "textura aberta" introduzida por Hart na teoria do Direito foi emprestada das teorias filosóficas sobre linguagem e significado da metade do século XX, embora, como será possível perceber, o autor tenha modificado a ideia da expressão ao atribui-la no estudo dos fenômenos jurídicos.

É nesse contexto que o presente trabalho se propõe a apresentar algumas reflexões referentes ao que Hart teria pretendido ao referir que o Direito possui uma "textura aberta". Para tanto, serão examinados e investigados quais possivelmente seriam os significados dessa textura, as extensões a ela atribuídas e as implicações dela decorrentes no âmbito da decisão judicial, a partir da análise dos textos originais do autor e dos entendimentos apurados por diversos estudiosos do Direito.

A abordagem será feita a partir do método indutivo, com objetivo explicativo, e procedimento bibliográfico, baseado principalmente nas obras de H.L.A Hart, além dos escritos de outros autores notadamente da área da filosofia do direito.

\section{A função do direito, a sua "textura aberta" e a discricionariedade judicial}

No contexto do modelo de Direito apresentado por Hart, o autor esclarece que as regras gerais estão entre os principais instrumentos de controle social do Direito, pois sem que, através delas, "multidões de indivíduos pudessem perceber, sem ulteriores directivas, padrões esses exigindo deles certa conduta conforme as ocasiões, nada daquilo que agora reconhecemos como direito poderia existir" (HART, 2001, 137 p.). Segundo o autor, é por essa razão que o Direito se utiliza de dois meios diferentes para comunicar certos padrões gerais de conduta aos indivíduos, a saber: a legislação - que predominante faz uso máximo de palavras gerais para se referir à categorias de pessoas, atos, coisas e circunstâncias - e o 
precedente - que, por outro lado, faz uso mínimo, para reconhecer a casos e categorias particulares a incidência naquelas classificações gerais.

Desde já, importa observar que o uso do precedente não seria meio hábil para eliminar a incerteza quanto à aplicação ou não das expressões gerais previstas nas regras em certos casos. Isso porque "estes cânones (de interpretação) são eles próprios regras gerais sobre o uso da linguagem e utilizam termos gerais que, eles próprios, exigem interpretação" (HART, 2001, 139 p.). Ainda assim, Hart observa que o uso do precedente poderá servir para atenuar as incertezas diante das expressões gerais contidas na regra, na medida em que àquela pessoa que recorre ao precedente verifica que "o poder discricionário que assim lhe é deixado pela linguagem pode ser muito amplo; a linguagem de tal forma que, se ela aplicar a regra, a conclusão constitui na verdade uma escolha, ainda que possa não ser arbitrária e irracional." (HART, 2001, 140 p.)

O autor esclarece que haverá casos em que os padrões de comportamentos (comunicados tanto pela via da legislação, quanto pela dos precedentes) serão percebidos “indeterminados em certo ponto em que a sua aplicação esteja em questão; possuirão aquilo que foi designado como textura aberta" (HART, 2001, 141 p.).

Diante disso, percebe-se que, para Hart, a textura aberta e a indeterminação das normas jurídicas são conceitos relacionados (HEIZE, 2004, 28 p.). Isso porque é possível identificar que "mesmo quando são usadas regras gerais formuladas verbalmente, podem, em casos particulares concretos, surgir incertezas quanto à forma de comportamento exigido por elas" (HART, 2001, 139 p.), o que -uma vez que o direito tem a função de comunicar padrões gerais de conduta aos cidadãos e oficiais justamente através do uso da linguagemprontamente se pode atribuir como decorrente da existência de um limite linguístico, natural à própria linguagem humana, que, em certas situações fáticas, não é capaz de alcançar as inovações naturais ou inventivas.

A textura aberta, na concepção de Hart, seria aquilo que se observa "quando termos normativos, ou as normas como um todo, são incertas em sua aplicação nos casos fronteiriços" (BIX, 2012, 200 p.). Destaca-se que essa incerteza ocorre naquilo que o autor chama de zona de penumbra, na qual estão os casos fronteiriços, os que se afastam do núcleo de significado do termo geral, eis que, nas palavras de Hart, "deve haver um núcleo de significado estabelecido, mas haverá igualmente uma zona de penumbra de casos discutíveis 
nos quais as palavras não são obviamente aplicáveis, nem obviamente eliminadas" (HART, 1958, 607 p.).

Segundo Roger Shiner, teriam sido apresentadas muitas imagens espaciais por Hart para explicar a textura aberta e a discricionariedade judicial, o que teria ajudado "a obscurecer, ao invés de iluminar, os aspectos do raciocínio jurídico e da decisão da commom law que Hart com razão, pensou, no contexto do conflito entre formalismo e ceticismo de regras, que ele precisava enfatizar" (SHINER, 2011, 359 p.). Sobre isso:

quando ele não está usando a terminologia simples das disputas 'reguladas' e 'não reguladas', a imagem de Hart é essencialmente espacial. Ele usa expressões como 'lacunas na lei', 'poderes interstiticiais', 'textura aberta', 'areas de conduta', 'area de textura aberta e atividade judicial dentro dela', 'nas margen das regras e nos campos deixados abertos pelos precedentes', 'um campo amplo e importante deixado aberto', 'nada para circunscrever a área de textura aberta', ' o núcleo a penúmbra', 'dentro da regra', 'situado na fronteira da regra', e assim por diante. (SHINER, 2011, 345 p.)

Pela observação dos diversos termos mencionados, percebe-se a importância de buscar compreender o que Hart pretendera ao empregar tal expressão de textura aberta e todas as outras a ela associadas, na medida em que, uma vez que elas sejam retiradas, "o que resta é uma consideração importante da criação de regras jurídicas da commom law, como uma certa espécie de raciocínio que pondera a necessidade de certeza do direito contra a sua necessidade de flexibilidade" (SHINER, 2011, 360-361 p.)

Tal consideração da criação de regras da commom law, ou das próprias regras em geral, fica mais evidente com a publicação de um Pós Escrito póstumo, na edição de 1994 de "O Conceito de Direito", na qual reafirmou-se a ocorrência do exercício do poder discricionário do juiz, para fins de criar o direito, nos casos em que este se apresente como parcialmente indeterminado ou incompleto - justamente em decorrência da dita "textura aberta".

Como resposta às críticas de Dworkin a respeito da teoria de Hart, foi esclarecido neste Pós Escrito que os poderes atribuídos aos magistrados seriam intersticiais -diferentemente do poder consideravelmente liberto que possuem os legisladores-, ou seja, objetos de constrangimentos substantivos que estreitariam a sua escolha, a qual não seria tomada de forma arbitrária, nem irracional, notadamente considerando que identificada com a respectiva regra de reconhecimento.

Em outras palavras, Hart estabelece que a criação pelo magistrado de uma resposta para o caso em face da textura aberta do Direito pode ser determinada através da 
discricionariedade do julgador, ao qual é dada a atribuição de escolha (considerada racional e não arbitrária), entre as diversas opções existentes, de significado à norma. No entanto, mostra-se necessário apontar que, conforme se extrai da leitura do trecho a seguir do PósEscrito de O Conceito de Direito, não foram esclarecidos quais seriam as razões ou os padrões a serem operados pelo magistrado quando do exercício do seu poder discricionário:

\begin{abstract}
Mas não deve [o juiz] fazer isso de forma arbitrária: isto é, ele deve sempre ter certas razões gerais para justificar a sua decisão e deve agir como um legislador consciencioso agiria, decidindo de acordo com as suas próprias crenças e valores. Mas se ele satisfizer estas condições, tem o direito de observar padrões e razões para a decisão, que não são ditadas pelo direito e podem diferir dos seguidos por outros juízes confrontados com casos difíceis semelhantes. [grifou-se] (HART, 2001, 336 p.)
\end{abstract}

De todo o modo, para Hart, o referido poder do juiz de resolver os litígios que o direito previamente estabelecido não consegue regular é tido como o "preço necessário que se tem de pagar para evitar o inconveniente de métodos alternativas de regulamentação desses litígios [...] o preço pode parecer baixo se os juízes forem limitados no exercício destes poderes e não puderem modelar códigos ou amplas reformas" (HART, 2001, 338 p.).

Em virtude disso, foram desenvolvidos dois argumentos em defesa de tal poder de criação do Direito pelos magistrados, quais sejam: a) o de que isso "constitui um traço familiar das democracias modernas e tal delegação ao Poder Judiciário não parece constituir uma ameaça mais séria a democracia" (HART, 2001, 338 p.) e b) o de que seria irrelevante tratar isso como uma forma de criação do direito ex post facto diante de casos difíceis -o que poderia ser considerado injusto, por possibilitar a frustração de expectativas-, eis que a respeito deles "o direito deixou regulados de forma de forma incompleta e em que não há um estado conhecido do direito, claramente estabelecido, que justifique expectativas" (HART, 2001, 339 p.)

Assim, pode-se identificar que a chamada "textura aberta do Direito" envolve diretamente a necessidade de serem atribuídos poderes intersticiais aos magistrados. Dada a importância das suas implicações para a teoria da decisão judicial de Hart, mostra-se relevante o estudo referente ao seu sentido, sendo nesse contexto que o presente artigo se propõe a examinar e investigar quais seriam os aspectos e as possíveis extensões atribuídos à "textura aberta do Direito". 


\section{A textura aberta do direito e as texturas abertas da linguagem}

A indeterminação jurídica, como será demonstrado ao longo deste tópico, "é atribuível, ao menos em grande parte, a linguagem do direito. A linguagem jurídica é aberta o suficiente para permitir aos juízes determinarem como certos termos devem ser aplicados em alguns casos. H.L.A Hart descreveu esse aspecto da linguagem jurídica como sua "textura aberta"” (ANDERSON, 2006, 117 p).

Nesse ponto, para fins de compreender o duplo sentido de "linguagem" que poderiam ser alcançados pela textura aberta do direito, classificou-se que a indeterminação da linguagem pode se dar não apenas por uma imprecisão linguística das palavras ou termos empregados - por serem semanticamente vagas ou específicas do conhecimento jurídico-, mas também por uma contextualização da linguagem. Explica-se.

A respeito das expressões e frases utilizadas pela legislatura, Marta Chromä refere que frequentemente estas são "semanticamente indeterminadas (abertas) ou vagas (e.g 'morte pelo parto' que, embora não seja medicamente certa, seria substancialmente certa ou mais provável) ou expressões que abordam 'clichés' jurídicos (e.g 'sem dúvida razoável')" (CHROM̈̈, 2005, 385 p.). Entretanto, algumas provisões seriam apenas "legalmente indeterminadas, enquanto a sua interpretação requer um certo grau de conhecimento jurídico para o fim de se aplicar ao evento concreto" (СHROM $\ddot{A}, 2005,385$ p.), conforme exemplifica:

\footnotetext{
'Uma pessoa que intencionalmente ou imprudentemente cause lesão a outrem, sem o seu consentimento, é culpada da ofensa de causar lesões ilegais'. Existem diversas perguntas interpretativas nessa provisão e vamos mencionar duas para ilustrar nosso ponto: (a) será que 'intencionalmente ou imprudentemente' significariam tanto 'intencionalmente' ou 'imprudentemente', ou seria possível a combinação de ambas (provavelmente seguida por uma sentença mais severa); e (b) será que a frase 'sem o seu consentimento' realmente significaria que se alguém ferir alguma parte do corpo de outrem com o consentimento do último (o que pode ocorrer em algumas situações extremas, frequentemente motivadas sexualmente) o ofensor não seria punido? Essas são as indeterminações legais resultantes de uma determinada provisão semântica. (CHROMÄ, 2005, 385 p.)
}

Isso porque a lei "deve ser escrita de tal forma que seja percebida como genericamente vinculante, i.e, a lei não é normalmente adotada para regular uma situação particular em um contexto particular, mas para governar o maior número possível de situações similares e 
contextos" (CHROMÄ, 2005, 385 p.). A partir dessa ideia, é possível identificar o porquê "os termos jurídicos podem ser vagos e não bem definidos, levando ao problema da 'textura aberta' no raciocínio jurídico" (VALENTE; BREUKER, 1991, 42 p.).

Nesse sentido, a maioria das palavras de um estatuto, de acordo com Derk Venema, "necessitam de uma certa quantidade de abertura para serem aplicáveis a uma vasta variedade de casos, e os juízes necessitam de uma certa medida de liberdade em determinar o significado e relevância dessas palavras.” (VENEMA, 2004, 139 p.).

É por tal motivo que, embora o legislador possa involuntariamente acabar empregando termos e expressões indeterminadas, isso também ocorre mediante a livre escolha pela indeterminação, tendo em vista a necessidade de generalização da regra, razão pela qual aquele que legisla "frequentemente usa palavras genéricas intencionalmente na crença de que juízes são os mais adeptos em preencher nos detalhes" (FREEMAN, 1994, 1.293 p.). Anne Wagner, ao esclarecer sobre as acepções da textura aberta da linguagem, didaticamente divide os dois níveis em que ela se opera, a saber o nível da indeterminação voluntaria ou involuntariamente presente na lei e o da modificação leve dos significados das palavras/conceitos, ou até "implementação" radical de novos em sua ratio decidendi, pelos juízes (WAGNER, 2005, 174-175 p.)

Nas palavras de Uri Jakob Schild "a textura aberta é mais óbvia em conceitos vagos como 'atividades razoáveis' [...] entretanto, conceitos que aparentam ter um significado preciso também têm textura aberta" (SCHILD, 1989, 22 p.), tendo em vista que os tribunais podem adotar uma interpretação sobre determinado conceito diversa da anteriormente compreendida, conforme exemplifica:

Considere por exemplo o conceito: 'proprietário de uma casa' [owner of a house]. Esse conceito, que pode aparentar ter um significado bem definido, é frequentemente usado em nosso domínio de exemplos jurídicos: Um proprietário de uma casa é um autor competente no caso de perturbação do sossego. Vamos primeiro observar que nós estamos interessados no significado jurídico do conceito, o que não necessariamente coincide com o significado quotidiano. A seguir, nós podemos obviamente coletar casos em que o conceito 'proprietário de uma casa' aparece e extrai o seu significado particular em cada caso. Isso irá nos dar uma ideia geral sobre o conceito, mas não poderá nos suprir com a sua exata definição. Quando um novo caso vai ao tribunal, não há nenhum modo de fazer uma decisão $a$ priori sobre o autor ser, de fato, um 'proprietário de uma casa' ou não. O tribunal pode decidir adotar o que pode ser chamado de 'significado padrão', ou uma interpretação especial usada em um caso anterior (se eles forem diferentes). Não obstante, o tribunal pode também decidir dar inteiramente uma nova 
interpretação do conceito devido a certas novas circunstâncias relacionadas ao caso, as quais ele decide levar em consideração. (SCHILD, 1989, 21 p.)

Assim, através do processo de determinação pelo magistrado de um conceito jurídico indeterminado, a solução de um dado caso não será necessariamente a mesma para outro, uma vez que "a decisão jurídica envolve um momento social, político ou humano de indeterminação em direção à precisão em um dado tempo e espaço (i.e experiência momentânea)" (WAGNER, 2005, 180 p.). Lauren Mommers aponta para a alteração no significado atribuído pelo magistrado aos conceitos constantes na regra como resultado do contexto em que ela se manifesta: "o sentido de textura aberta muda através do tempo" (MOMMERS, 2010, 267 p.).

Dessa maneira, observa-se que "cada termo usado nos textos legais tem diferentes possibilidades de interpretação, i.e, não é certo quando ou não um certo fato ou entidade no mundo real combina com o termo escrito no texto legal" (VALENTE; BREUKER, 1991). É possível verificar que "até mesmo as regras mais detalhadas têm uma textura aberta e, assim, necessitam ser interpretadas, mas, pelo menos, o espaço deixado para a discricionariedade dos juízes será menor" (VENEMA, 2004, 144 p.).

Aponta-se que "o direito é intrinsecamente uma textura aberta. Ele tem uma definição precisa apenas para aqueles casos individuais que tenham chegado ao tribunal e sido decididos; não há definição precisa para o que ainda está a ser julgado.” (SCHILD, 1989, 23 p.). Logo, a indeterminação -que é "uma característica das representações dos fatos" (WILLIAMSON, 1994, 249 p.) - irá “apenas cessar quando uma experiencia momentânea (i.e um caso no tribunal) for considerada. A indeterminação então se tornará em contextualizada e/ou relativa determinação" (WAGNER, 2005, 180 p.). Quer dizer, "antes da decisão do tribunal, o direito é incompleto" (ANDERSON, 2006, 126 p.).

É nesse sentido que, como mencionado anteriormente, a discricionariedade do magistrado -que se opera conforme os elementos próprios do contexto por ele vivenciado- é concebida por Hart como consequência associada à textura aberta do Direito. Isso dado que "a textura aberta de uma provisão legislativa, assim como a abertura de uma regra jurídica como um todo, deixa algum poder para o seu interprete" (CHROMÄ, 2005, 385 p.), ou seja, em outras palavras, "a interpretação e aplicação de textos normativos semanticamente abertos - e todos os textos em alguma mistura o são - chamam a discricionariedade do intérprete" (CHESSA, 2014, 283 p.). 
Assim, consoante a teoria de Hart, a indeterminação do Direito pode ser causada pela abertura que existe na própria linguagem jurídica, o que é responsável pela atribuição de discricionariedade aos magistrados, conforme esclarece Scott Anderson:

\begin{abstract}
A linguagem jurídica, assim como qualquer linguagem natural, permite que aos usuários da linguagem alguma discricionariedade em determinar como ela será aplicada em certos casos. Hart afirma que a natureza de textura aberta da linguagem deu discricionariedade aos juízes para aplicarem regras jurídicas em casos fora do núcleo da regra, mas dentro da sua penumbra. (ANDERSON, 2006, 117 p.)
\end{abstract}

Portanto, pode-se dizer que "Hart via a linguagem [...] como explicação da inevitabilidade da discricionariedade judicial" (BIX, 1993), notadamente considerando que tanto a generalização, quanto a variação conforme o contexto, são características adequadas à concepção das regras. Dito isso, foi possível identificar que a linguagem por elas utilizada compreende (tanto involuntária, quanto voluntariamente) o uso de expressões i) linguisticamente gerais e indeterminadas e ii) linguisticamente precisas e contextualmente indeterminadas, as quais, quando no âmbito da decisão judicial, viriam a ser interpretadas pelo magistrado para fins de que, no exercício de seu poder intersticial, fossem determinadas e aplicadas consoante os detalhes do caso concreto.

\title{
4. A textura aberta do Direito e a derrotabilidade
}

Segundo Brian Bix, a preocupação de Hart não estaria em desenvolver uma filosofia geral da linguagem, mas em como as regras são e deveriam ser aplicadas: "Hart não provou pela natureza da linguagem que os juízes devem ter discricionariedade; precisamente, ele deu razões porque os textos legais devem ser interpretados de modo que deixe aos juízes discricionariedade ao aplicar a lei”(BIX, 1991, 66 p.).

Nesse contexto, reconhece-se que não foi apenas a ideia de "textura aberta" que Hart introduziu na teoria do Direito, mas também a de "derrotabilidade", em 1948-1949, com a publicação do ensaio "The Ascription of Responsibility and Rights".

Hart estabelece que os conceitos jurídicos são essencialmente derrotáveis, ou excepcionáveis, o que é exemplificado a partir do conceito legal de contrato. Sobre isso, embora seja necessário que as condições positivas requeridas para a sua existência enquanto contrato válido sejam apresentadas, isso não seria suficiente, porquanto ainda seria necessário

Revista de Teorias do Direito e Realismo Jurídico | e-ISSN: 2525-9601 | Porto Alegre | v. 4 | n. 2 | p. $21-37$ | Jul/Dez. 2018 
verificar o que -a existência de uma condição/cláusula unless- pode excepcionar um pleito de que um contrato é contrato válido, mesmo que todas as condições positivas sejam satisfeitas (HART, 1948-1949, 175 p.). O autor ilustra a ocorrência de exceções/defesas extremamente heterogêneas que, de maneiras diversas, serviriam para excepcionar ou enfraquecer reivindicações no contrato, entre as quais estão as declarações falsas, a coação, a demência, os contratos destinados a perverter o curso da justiça, o surgimento de uma guerra. (HART, 1948-1949, 176 p.).

É importante notar que, no caso da derrotabilidade, haverá uma formulação clara da regra que deixará de ser observada no momento de aplicação diante de um caso particular (HART, 1948-1949, 175 p.). Portanto, Hart entende que os conceitos jurídicos, embora estejam acompanhados das condições necessárias, não estão de todas as condições suficientes - haja vista que sempre pode haver uma condição que os derrote.

Nas palavras de Frederick Schauer, a chave da ideia de derrotabilidade é "o potencial para algum aplicador, interprete ou executor de uma regra fazer uma adaptação ad hoc ou sob o impulso do momento para o fim de evitar um insuficiente, ineficiente, injusto, iníquo, ou de outro modo inaceitável resultado da regra" (SCHAUER, 2010, 07 p.). A esse respeito, Neil Maccormick esclarece o raciocínio jurídico feito diante da derrotabilidade, estabelecendo que o derrotável não é o conceito em si, mas a afirmação das condições que o representam em certos casos:

O 'direito' [right] é, no final das contas, um objeto teórico, um fato institucional. Tais fatos existem apenas onde existe perfeita e não-derrotada satisfação de todas as condições (as implícitas, bem como as explicitas) de fato requeridas em um dado caso. É a atribuição de um direito, ou a afirmação de uma reivindicação a ele (ou àquilo que se pretende ser autorizado pelo direito, e.g, pagamento da pensão de viuvez) que pode ser derrotado, não o direito em si mesmo. Então não é, afinal, o conceito que é derrotável, mas alguma afirmação formulada das condições para representar o conceito em certos casos, ou alguma asserção, atribuição ou reivindicação baseada em um certo entendimento dessas condições. (MACCORMICK , 1995, 102 p.)

Pois bem, segundo Calvin Schrag, a razão enquanto manifestação do discurso humano se processa em uma textura aberta, ao passar por uma indeterminação decorrente do espaço temporal transversal entre o passado e o presente:

a dinâmica da razão enquanto manifestação do discurso segue as linhas da transversalidade [...] [as quais] também atravessam um horizonte potencial, projetado em uma região de possibilidades futuras, aquilo que não foi ainda 
dito e não foi ainda feito, com que a concrescência do passado com o presente é reaberta e transvalorizada determinando a textura do passado e presente como uma 'textura aberta'(SCHRAG, 2012, 73 p.).

No campo da aplicação do Direito, quando uma vagueza intencional é introduzida por um conceito de textura aberta na lei, tal pode ser explicado pelo fato de que "o significado é tão dependente das circunstâncias individuais que nenhum legislador poderia esperar prever cada possibilidade e criar uma provisão para ela" (SCHILD, 1989, 23 p.), razão pela qual é deixado um espaço para o julgamento discricionário. Dessa forma, um conceito é tido como de textura aberta "se as condições para a sua aplicação não são fortemente indicadas, mas, em vez disso, são deixadas para serem resolvidas pelos tribunais à luz das circunstâncias dos casos individuais" (BENCH-CAPON; VISSER, 1997, 192 p.)

Logo, poder-se-ia cogitar atribuir à ideia de derrotabilidade o aspecto de manifestação da textura aberta do Direito, no sentido de que esta possui um viés relacionado à impossibilidade -decorrente da limitação humana e da consequente insuficiência da sua própria linguagem- de serem previstas todas as condições suficientes de uma norma. Tal decorreria do fato de que, embora o legislador possa delinear todas as condições entendidas como necessárias à efetivação da norma, poderia não estar ao seu alcance condições outras compreendidas como suficientes a contemplar futuros casos concretos de discutível solução quanto à norma aplicável. Sobre isso, para Hart:

os humanos criadores do direito não podem o conhecimento de todas as possíveis combinações de circunstâncias as quais o futuro pode trazer. Isso significa que todas as regras jurídicas e conceitos são 'abertos': e quando um caso não previsto surgir nós devemos fazer uma nova escolha, e, ao fazê-la, elaborar nossos conceitos jurídicos, adaptando-os aos fins socialmente desejáveis. (HART, 1983, 270 p.)

É nesse sentido que seria natural da condição humana a concepção de regras gerais, que "envolvessem no ponto de aplicação efetiva, uma escolha nova entre alternativas abertas" (HART, 2001, 141 p.), porquanto os homens detêm não apenas aquilo que Hart chama de relativa ignorância de fato - o que se manifesta na medida em que "os legisladores humanos não podem ter tal conhecimento de todas as possíveis combinações de circunstâncias que o futuro pode trazer" (HART, 2001, 141 p.) - mas também a chamada relativa indeterminação de finalidade -o que surge como consequência dessa incapacidade de antecipar, ou seja, diante de casos que deixaram de ser considerados inicialmente ou não puderam sê-lo. 
Tanto o é que Hart exemplifica o ponto da textura aberta do Direito, em O Conceito de Direito, com a regra que prevê que nenhum veículo pode ser levado para um parque, cuja finalidade atribuída pelo legislador é determinada por conta da escolha pelos casos claros (automóvel, autocarro, motociclo), mas tornar-se-ia indeterminada se a regra fosse confrontada com uma situação que não houvesse sido prevista, como um automóvel elétrico de brinquedo (HART, 2001, 142 p.)

Para Scott Shapiro, de acordo com Hart, a partir da textura aberta da linguagem, "a discricionariedade judicial é um subproduto da indeterminação inerente da orientação social. É impossível [...] transmitir aos outros padrões de conduta que estabeleçam antecipadamente cada contingência" (SHAPIRO, 2007, 16 p.). Assim, a derrotabilidade também poderia estar inserida como parte da ideia de textura aberta do Direito para Hart, inclusive considerando o abrangente argumento extraído de sua obra no que tange à existência de "áreas de conduta em que muitas coisas devem ser deixadas para serem desenvolvidas pelos tribunais ou pelos funcionários, os quais determinam o equilíbrio, à luz das circunstâncias, entre interesses conflitantes que variam em peso, de caso para caso" (HART, 2001, 148 p.).

Além da legislação ter uma textura aberta, como visto no tópico anterior, quando estabelece padrões muito gerais para fazer referência a condutas nas quais os casos indivíduas são variados, isso também pode ser verificado na medida em que "as vezes, o significado de um predicado jurídico foi determinado pela prática e por fatos não-linguísticos e ainda assim a sua extensão não foi completamente determinada. Isso pode acontecer quando uma enorme variedade de casos possíveis pode se enquadrar na regra jurídica"(ANDERSON, 2006, 122123).

Então, segundo Patrícia Graeff, a textura aberta do direito seria um fenômeno mais amplo do que a textura aberta da linguagem, na medida que "Hart está nominando sob um termo geral diferentes formas de indeterminação jurídica, o que inclui tanto a vagueza stricto sensu, quanto a textura aberta da linguagem, e, ainda a derrotabilidade" (GRAEFF, 2015, 48 p.). Para a autora, a vagueza stricto sensu, que não estaria inserida na textura aberta da linguagem, seria uma questão de grau no que diz respeito à distinção entre o caso fronteiriço e o caso claro, dando "origem ao que se chama de um paradoxo sorites, que se caracteriza pelo princípio da tolerância, segundo o qual pequenas modificações no objeto não afetam a aplicação do conceito" (GRAEFF, 2015, 48 p.). 
Também nesse sentido, Andrew Stranieri e John Zeleznikow entendem que efetivamente uma outra espécie de textura aberta "surge da derrotabilidade de conceitos jurídicos e regras. Qualquer conceito ou regra, não importa o quão bem definida, é sempre aberta a repreensão. Raramente as premissas ou consequências que existem no direito são universalmente aceitas” (STRANIERI; ZELEZNIKOW, 1998, 103 p.).

Não obstante, esclarece-se que não há consenso no que diz respeito à relação que haveria entre a ideia de textura aberta do Direito e a de derrotabilidade. Isso porque, para Brian Bix, as expressões "textura aberta" e "derrotabilidade" se tratam de fenômenos distintos, os quais, todavia, produzem resultados cujas implicações se identificam, eis que "a textura aberta e a derrotabilidade hartianas são, no máximo, amplamente análogas no sentido de que ambas criam circunstâncias nas quais os juízes têm discrição para criar novo direito ou exceções ao direito existente" (BIX, 2012, 193 p.). Bix elucida que o raciocínio a ser feito é o de que o rótulo da derrotabilidade é usado onde uma "conclusão inicial é garantida, sujeita a revisão posterior ou superação quando surjam fatos adicionais. Pelo contrário, a textura aberta hartiana é sobre incerteza, um conjunto de (igualmente, ou, no mínimo, comparavelmente) decisões legítimas" (BIX, 2012, 200 p.).

Diante disso, qualquer conexão de identificação entre a textura aberta e a derrotabilidade estaria relacionada ao fato de que "que ambas foram (e são) usadas para explicar e justificar a discrição judicial e (assim) a criação do direito pelo judiciário" (BIX, 2012, 200 p.), na medida em que "as formas do raciocínio jurídico da derrotabilidade criam (quando confrontam o tipo certo de situação fática) a mesma espécie de gama de escolhas disponíveis que os juízes enfrentam na 'textura aberta' hartiana dos casos fronteiriços” (BIX, 2012, 200 p.).

Frederick Schauer, por sua vez, sustenta que, no Direito, não haveria qualquer outro elemento de indeterminação além da própria textura aberta da linguagem por ele utilizada eis que não entende a derrotabilidade como algo inerente ao direito e que lhe cause indeterminação. Dessa forma, a textura aberta do Direito concebida por Hart seria equivalente à própria textura aberta da linguagem, não se incluindo nela -nem residualmente- quaisquer considerações sobre a derrotabilidade, na medida em que: "até onde a linguagem é uma textura aberta, então também necessariamente é o direito" (SCHAUER, 2011, 23 p.). Para ele, a derrotabilidade não seria algo inerente ao direito, haja vista que, com alguma frequência, os magistrados aplicam uma regra consoante o seu significado literal, desconsiderando o 
contexto em que é usada em uma ocasião particular, razão pela qual, "seria um erro descrever a derrotabilidade das regras jurídicas como um aspecto universal ou até majoritariamente comum da tomada de decisão pelos juízes e pela instituição que nós comumente chamamos de 'sistema jurídico"” (SCHAUER, 2010, 12-13 p.).

\section{Considerações Finais}

Pela observação dos aspectos analisados no presente artigo, é clara a conexão da expressão "textura aberta do Direito", proposta por Hart, com o modelo de regras jurídicas a serem aplicadas considerando o poder atribuído aos magistrados de criarem o direito quando enfrentarem os ditos “casos fronteiriços". Nesse sentido, mostra-se relevante investigar em que poderia consistir a ideia hartiana de que o Direito possui uma textura aberta.

Embora inexista uma resposta concreta, ao longo do presente artigo algumas hipóteses puderam ser levantadas a respeito da abrangência daquilo que Hart considera como "textura aberta do Direito", então responsável pela discricionariedade judicial. Nesse sentido, ponderou-se se tal textura aberta i) estaria associada exclusivamente à textura aberta da linguagem - a qual, por sua vez, poderia dizer respeito não apenas à linguagem em um viés puramente semântico ou técnico (através do uso de expressões linguisticamente gerais e indeterminadas), mas também à linguagem contextualizada (pelo uso de termos linguisticamente precisos e contextualmente indeterminados)- e ii) incluiria também a derrotabilidade das normas no raciocínio jurídico operado para a decisão judicial.

Isso porque foi possível identificar que os padrões jurídicos são inicialmente vagos ou indeterminados a partir das incertezas das leis ou da qualificação imperfeita delas por precedentes - as quais podem ser atribuídas à limitação da linguagem, do raciocínio e do discurso humanos. Ou seja, o Direito teria uma textura aberta, seja por entraves da própria linguística, pela necessidade de alterações contextuais na linguagem, ou pela impossibilidade de previsão e antecipação de todas as condições suficientes.

\section{Referências Bibliográficas}


ANDERSON, Scott Alan. Legal indeterminacy in context. 2006. 258 f. Dissertação (Doutorado em Filosofia) - Ohio State University, Columbus, 2006, 105 p.

BENCH-CAPON, Trevor J.M.; VISSER, Pepijn R.S. Open Texture and Ontologies in Legal Information Systems. In. Proceedings of the 8th International Workshop on Database and Expert Systems Applications., New York: IEEE Press, 1997

BIX, Brian H, Defeasibility and open texture. In. BELTRÁN, Jordi Ferrer Beltrán; BATTISTA, Giovanni . The logic of legal requirements: essays on defeasibility. Oxford: Oxford University Press, 2012

H.L.A hart and the "open texture" of language. Law and Philosophy, Oxford, v. 10, p. 51-72, fev. 1991;

Law, language and legal determinacy. Oxford: Clarendon Press, 1993

CHESSA, Omar. I giudici del diritto. Problemi teorici della giustizia costituzionale. Milano: FrancoAngeli, 2014

CHROMÄ, Marta. Indeterminacy in criminal legislation. In. BHATIA, Vijay Kumar; ENGBERG Jan. Vagueness in normative texts. Bern: Peter Lang, 2005

FREEMAN, M.D.A. Llyod's introduction to jurisprudence. London: Sweet \& Maxwell, 1994

HART, H. L. A. Essays in jurisprudence and philosophy. Oxford: Clarendon Press, 1983

O conceito de direito. Tradução de Armindo Ribeiro Mendes. 3. ed. Lisboa: Fundação Calouste Gulbenkian, 2001

. Positivism and the separation of law and morals. Harvard Law Review, Cambridge, v. 71, n. 4. pp. 593-629. fev. 1958.

Revista de Teorias do Direito e Realismo Jurídico | e-ISSN: 2525-9601 | Porto Alegre | v. 4 | n. 2 | p. $21-37$ | Jul/Dez. 2018 
The Ascription of responsibility and rights. Proceedings of the Aristotelian Society, New Series, v. 49, 1948 - 1949, pp. 171-194. Hoboken: Wiley

HEIZE, Eric. The logic of liberal rights: a study in the formal analysis of legal discourse. Abingdon: Routledge, 2004

MACCORMICK, Neil. Defeasibility in law and logic. In. BANKOWSKI, Zenon; et al. (eds.), Informatics and the foundations of legal reasoning. Dordrecht: Springer Science Business Media, 1995

MOMMERS, Laurens. Ontologies in the legal domain. In. POLI, R.; SEIBT, J. (eds). Theory and applications of ontology: philosophical perspectives. Berlin: Springer Science Business Media, 2010

SCHAUER, Frederick. Is defeasibility an essential property of law? In. FERRER, J.; RATTI, C. (eds.). Law and defeasibility. Oxford: Oxford University Press, 2010 . Disponível em $<$ https://ssrn.com/abstract=1403284>. Acesso 27/06/2018

. On the open texture of law. Virginia Public Law and Legal Theory Research Paper n. 35, 2011. Disponível em <https://ssrn.com/abstract=1926926>. Acesso 26/06/2018.

SCHILD, Uri Jakob. Open-textured law, expert systems and logic programming (1989). Tese (Doutorado em Filosofia) - Departament of Computing Imperial College of Science and Technology , University of London, London, 222 f. ,1989

SHAPIRO, Scott J. The 'hart-dworkin' debate: a short huide for the perplexed. Public Law and Legal Theory Working Paper Series, Ann Arbor, n. 22, march 2007

SHINER, Roger A. Hart on judicial discretion. Problema: Anuario de Filosofía y Teoría del Derecho, Ciudad de México, n. 5, pp. 341-362, 2011, 345 p. Disponível em :<http://www.redalyc.org/articulo.oa?id=421940003015>. Acesso: 08 jul. 2018

Revista de Teorias do Direito e Realismo Jurídico | e-ISSN: 2525-9601 | Porto Alegre | v. 4 | n. 2 | p. 21 - 37 | Jul/Dez. 2018 
STRANIERI, Andrew; ZELEZNIKOW, John. The role of open texture and stare decisis in data mining discretion, Jurix, 1998. Disponível em <http://jurix.nl/pdf/j98-08.pdf>. Acesso: 02 jul. 2018

VALENTE, André; BREUKER, Joost. Law functions: Modelling principles in legal reasoning: In. BREUKER, J.A.P.J.; DE MULDER, R.V.; HAGE, J.C. (eds.). Legal knowledge based systems JURIX 91: Model-based legal reasoning, The Foundation for Legal Knowledge Systems. Lelystad: Koninklijke Vermande, 1991

VENEMA, Derk. Judicial discretion: a necessary evil? In. HIMMA, Kennet Einer (Coord.). Law, morality, and legal positivism: proceedings of the 21st world congress of the international association for philosophy of law and social philosophy (ivr). Stuttgart: Franz Steiner Verlag, 2004

WAGNER, Anne. Samiotic analysis of the multistage dynamic at the core of indeterminacy in legal language In. BHATIA, Vijay Kumar; ENGBERG Jan. Vagueness in normative texts. Bern: Peter Lang, 2005

WILLIAMSON, Timothy. Vagueness. London: Routledge, 1994 